Bulletin UASVM Food Science and Technology 70(1)/2013, 16-24

ISSN-L 2344-2344; Print ISSN 2344-2344; Electronic ISSN 2344-5300

\title{
Characterisation of an Aromatic Plant-based Formula using UV-Vis Spectroscopy, LC- ESI(+)QTOF-MS and HPLC-DAD Analysis
}

\author{
Florina BUNGHEZ ${ }^{1)}$, Carmen SOCACIU ${ }^{1,2)}$, Florina ZĂGREAN ${ }^{1,2)}$, Raluca Maria \\ POP $^{2,3)}$, Floricuţa RANGA ${ }^{1)}$, Florina ROMANCIUC ${ }^{1)}$ \\ ${ }^{1)}$ University of Agricultural Sciences and Veterinary Medicine, Faculty of Agriculture, 3-5 Mănăştur \\ Street, Cluj-Napoca, Romania; e-mail: florinabunghez@gmail.com \\ ${ }^{2)}$ Center for Applied Biotechnology CCD-BIODIATEC, Proplanta Cluj-Napoca, Romania \\ ${ }^{3)}$ University of Medicine and Pharmacy "Iuliu Haţieganu" Cluj-Napoca, Victor Babes, 8, Cluj- \\ Napoca, Romania
}

\begin{abstract}
In the present study seven aromatic herbs (basil, thyme, oregano, rosemary, clove, cinnamon and sage) were investigated and a new product was developed using a default recipe. The characterization of each plant aimed to identify the specific "fingerprint" by its main bioactive molecules and the "traceability" of these molecules in the new product.In order to determine the main bioactive compounds of the individual plants composition, in comparison with the new formula, high throughput techniques like UV-Vis spectroscopy, HPLC-DAD and LC-ESI (+)QTOF-MS were used. Based on UV-Vis spectral fingerprint ( $200-650 \mathrm{~nm}$ ), it was calculated the extraction efficiency of different phenolic derivatives, higher values of phenolic acids being observed for cinnamon, rosemary, sage, while rosemary ansd sage had higher values for flavonoids. The richest content of phenolic derivatives was observed for rosemary followed by clove, cinnamon, oregano, thyme, basil and sage, in a range from 136.249 to $271.164 \mathrm{mg} \mathrm{GAE} / 100 \mathrm{ml}$, while the concentration of phenolic compounds in the final products was $206 \mathrm{mg}$ GAE/100 ml. Using LC-ESI(+)-QTOF-MS and HPLC-DAD as accurate methods to identify the main biomarkers present in the aromatic herbs and EPC, there were separated 27 molecules and made their tentative structure assignement, based on international databases. The main biomarkers of the product were identified to be flavonols (quercetin, dihydroquercetin, isorhamnetin), flavanols (catechin, epicatechin, epigallocatechin), hydroxycinnaminic acids (caffeic acid, chlorogenic acid), stilbenes (resveratrol, trans-resveratrol) which may confer its antimicrobial.potential
\end{abstract}

Keywords: aromatic plants, phenolic compounds, antimicrobial product, HPLC-DAD, LC-QTOF-MS spectrometry, UV-Vis spectrometry

\section{INTRODUCTION}

Aromatic plants like basil, thyme, oregano, clove, cinnamon, sage, rosemary are excellent source of secondary metabolites, in particularly phenolic compounds (phenolic acids derivates, flavonoids) that are associated with antioxidative and antimicrobial action in all biological systems. In recent years, due to their diverse biological functions, phenols have received great attention (Yañez et al., 2013).

Phenolic acids are a major class of phenolic compounds, widely occurring in the plant kingdom especially in fruits and vegetables. Considerable variation was found in phenolic compounds of different species. Because of the diversity and complexity of the natural mixtures of phenolic compounds in hundreds of herb extracts, it is rather difficult to characterize every compound and elucidate its structure, but it is not difficult to identify major groups and important aglycones of phenolic compounds. 
Many aromatic plants are rich in phenolic derivatives and their health-promoting properties were related to this composition (http://www.ars-grin.gov/duke/plants.html).

Recent studies revealed that highly positive relationships exist between the antibacterial activity and antioxidant capacity of the extracts (Shan et al., 2007). The results of this study emphasized the importance of phenolic compounds in the antibacterial activity of spice and herb extracts and also indicated that the phenolic compounds significantly contributed to their antibacterial activity (Delmas et al., 2009).

It is well known that the antioxidant activity increases with the number of $\mathrm{OH}$ groups and methoxy group. The catechol group has the property to enhance the radical scavenging activity of the molecules due to o-quinone formation. The antioxidant activity does not change in case of esterification of caffeic acid by quinic acid leading to chlorogenic acid. The glycosylation of quercetin in rutin decreases the antioxidant activity and the antimicrobial activity (Delmas et al., 2009).

The phenolic antioxidants can be also characterized by their ability to degrade cell membranes, revealing their antimicrobial activity. Their antimicrobial activity is well documentated in various studies (Delmas et al., 2009, Vauzour et al, 2012, Shan et al., 2007). Phenolic secondary metabolites can be defined as antimicrobials produced against invading pathogens and stress. In some cases the induction can be associated with the action of diphenolic oxidases (Vauzour et al., 2012).

The toxicity of phenols upon the bacterial cell is related to reaction with sulfhydryl groups of proteins causing the unavailability of the substrates to microorganism (Alzoreky, 2009). Phenols action is characterized by protein precipitation and enzyme inhibition of microorganism (Shan et al., 2007).

Therefore this study aims to individually investigate seven aromatic herbs (basil, thyme, oregano, rosemary, clove, cinnamon and sage) in order to develop a new nutraceutical. The characterisation of each plant aimed to identify the specific "fingerprint" by its main bioactive molecules and the "traceability" of these molecules in the new product using UVVis, HPLC-DAD, LC-ESI(+)QTOF-MS analysis.

\section{MATERIALS AND METHODS}

\section{Preparation of the plant extracts}

For the present study seven aromatic plants were selected: basil (Ocinum basilicum), thyme (Thymus vulgaris), oregano (Origani herba), sage (Salvia officinalis), cinnamon (Cinnamomi cortex), clove (Eugenia caryophyllata) and rosemary (Salvia officinalis). The plants were purchased from a Romanian plant market. The plants were dried at room temperature in absence of light and humidity, grounded and sived in order to obtain a soft powder.

The new plant based formula (EPC) was obtained by mixing the plant powders according to a default recipe (20\% basil, $10 \%$ thyme, $10 \%$ clove, $15 \%$ oregano, $15 \%$ rosemary, $15 \%$ sage, $15 \%$ cinnamon).

The selected aromatic plants and the new plant-based formula (EPC) were extracted in methanol $(95 \%)$ acidified with $1 \% \mathrm{HCl}$. The plant extracts and the new plant-based formula (EPC) were then sonicated $30 \mathrm{~min}$, centrifuged and filtered, in order to obtain a clear extract. The plant extracts and the new formula (EPC) were kept in deep freezer until the analysis.

\section{UV-VIS spectra and calculation of extraction factors}

The UV-Vis spectra was recorded (700-200 nm) for each plant extract and the new plant-based formula (EPC) using a Jasco V 530 spectrofotometer. There were identified the 
maxima wavelengths specific to polyphenols at $280-330 \mathrm{~nm}$, to flavonoids and quinones obtained by polyphenols oxidation at 390-420 nm and chlorophylls at 600-660 nm.

In case of each plant and for the new plant-based formula (EPC) the Extraction Factor (EF) was determined, considering the absorbtion values $\left(\mathrm{A}_{\lambda \max }\right)$, multiplied with the dilution factor $(\mathrm{d})$. (EPC).

The results were expressed in mean values per plant and new plant-based formula

\section{Total phenolic content}

The total phenolic content was determined by Folin-Ciocâlteu method (Folin. and Ciocalteu, 1927) using gallic acid as standard.

The calibration curve using different concentrations of pure gallic acid $(\mathrm{y}=$ $0.9443 \mathrm{x}+0.0608$ and $\mathrm{R}^{2}=0.9945$ ) was useful to calculate the GAE equivalents in each plant and EPC. Results were expressed as gallic acid equivalents (mgGAE)/100 ml extract).

\section{HPLC-DAD and LC-ESI(+)QTOF-MS analysis}

All plant extracts and EPC extract were diluted (1:1) with methanol and aliquots of 5 $\mu l$ of each sample were subjected to two types of chromatography, HPLC coupled with photodiode array detection (HPLC-DAD) and LC-ESI(+)QTOF-MS analysis, both using a Thermo Scientific HPLC UltiMate 3000 system equipped with a quaternary pump delivery system Dionex and MS detection by a Bruker Daltonics MaXis Impact device.

The plant metabolites were separated on the Thermo Scientific Acclaim $\mathrm{C}_{18}$ column $(3 \mu \mathrm{m}, 2.1 \times 50 \mathrm{~mm})$ at $40^{\circ} \mathrm{C}$. The mobile phase consisted of $0.1 \%$ formic acid in water (A) and $0.1 \%$ formic acid in acetonitrile (B). The flow rate was set at $0.5 \mathrm{~mL} \cdot \mathrm{min}^{-1}$. The gradient elution initial conditions were $1 \% \mathrm{~B}$ with linear gradient to $15 \% \mathrm{~B}$ from 0 to $3 \mathrm{~min}$, followed by linear gradient to $50 \% \mathrm{~B}$ at $6 \mathrm{~min}$, linear gradient to $95 \% \mathrm{~B}$ at $9 \mathrm{~min}$, isocratic on $95 \% \mathrm{~B}$ for $6 \mathrm{~min}$ and then returned to initial conditions at $15 \mathrm{~min}$ and kept isocractic on $1 \% \mathrm{~B}$ for 5 min. The DAD detector was set at $270 \mathrm{~nm}$. The separated molecules were introduced directly into the mass spectrometer by electrospray. The mass range was set between $50-1000 \mathrm{~m} / \mathrm{z}$, using a nebulizing gas pressure set at 2 bar, the drying gas flow at $8 \mathrm{~L} / \mathrm{min}$, the drying gas temp at $180{ }^{\circ} \mathrm{C}$. Before each separation run, a calibrant solution of sodium formate was injected. The control of the instrument and the data processing were done using TofControl 3.2 and Data Analysis 4.1 (Bruker Daltonics), respectively.

\section{RESULTS AND DISCUSSIONS}

\section{Extraction factors of bioactive compounds based on the UV-Vis spectra}

The comparative UV-Vis fingerprint (200-500 nm) of basil $v s$ thyme extract, clove $v s$ cinnamon extract, rosemary $v s$ sage and oregano extract, as well for EPC extract were represented in Fig. 1-4. 


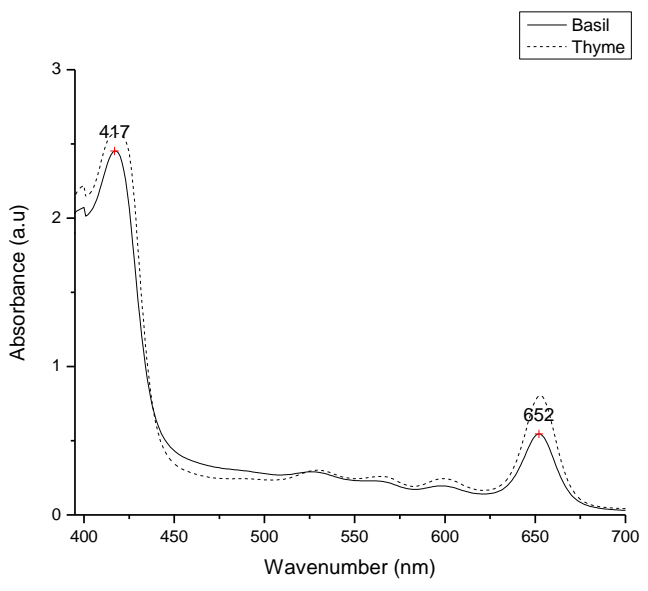

Fig. 1. Comparative UV-Vis fingerprint of basil and thyme extracts

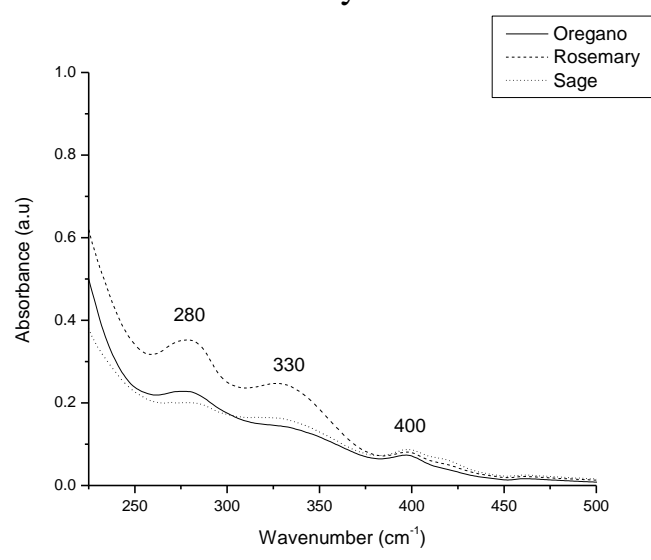

Fig. 3. Comparative UV-Vis fingerprint of oregano, rosemary and sage extract

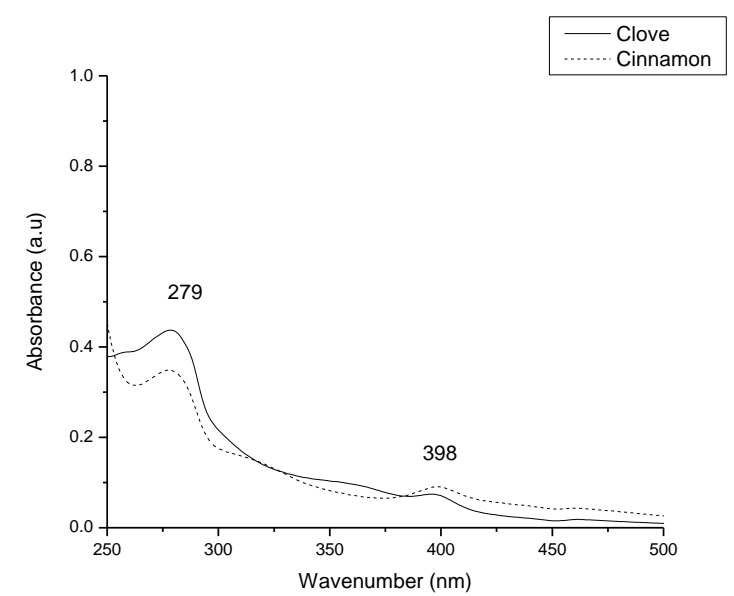

Fig. 2. Comparative UV-Vis fingerprint of clove and cinnamon extract

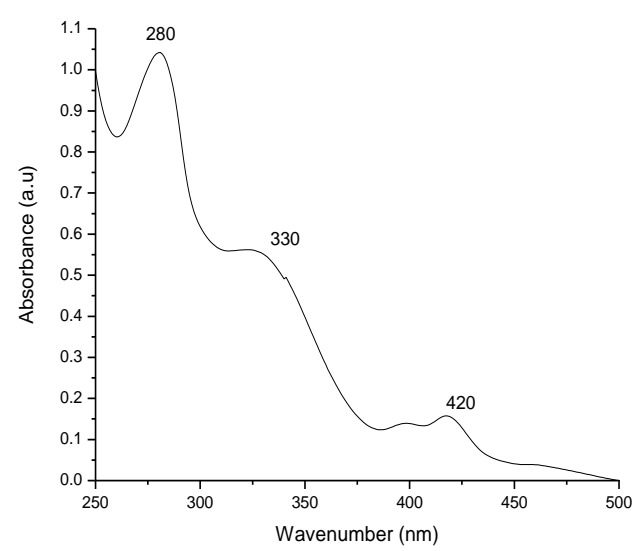

Fig. 4. UV-Vis fingerprint of EPC extract

According to the UV-Vis spectra of each plant we can observe that basil and thyme methanolic extracts contain quinones and chlorophylls (absoption peaks in the regions 400$412 \mathrm{~nm}$ and 600-660 nm region) (Fig.1), while clove, cinnamon, rosemary and sage (Fig. 2) are characterized by absorptions in the UV region $(220-280 \mathrm{~nm})$ and in the range $330-420 \mathrm{~nm}$, corresponding to phenolic acids and their derivatives (flavones, flavonols, phenylpropenes and quinones). In oregano, rosemary and sage we saw similar fingerprints, oregano being the richest in phenolic derivatives $(280 \mathrm{~nm}$ ) and flavonoids (around $330 \mathrm{~nm}$ ). The new plantbased formula (EPC) can be characterized by intense absorptions around $280 \mathrm{~nm}$ and also two peaks in the 330 and $420 \mathrm{~nm}$ region (Fig.4), indicating that it is rich in phenolic acids and their derivates.

Tab. 2 represents the specific absorbtion values for each plant extract and for the new plant-based formula (EPC) as well the extraction efficiency (EF factor) was calculated according to the formula described in Materials and Methods. 
Tab. 2

Specific absorption values for each plant and EPC extracts and EF values calculated (see Materials and methods)

\begin{tabular}{|c|c|c|c|c|c|c|}
\hline Plant & $\mathrm{A}_{220-280 \mathrm{~nm}}$ & $\begin{array}{c}\mathrm{EF}_{220-280 \mathrm{~nm}} \\
\text { (phenolic } \\
\text { acids) }\end{array}$ & $\mathrm{A}_{330-420 \mathrm{~nm}}$ & $\begin{array}{c}\mathrm{EF}_{330-420 \mathrm{~nm}} \\
\text { (flavonoids } \\
\text { and } \\
\text { quinines) }\end{array}$ & $\mathrm{A}_{600-660 \mathrm{~nm}}$ & $\begin{array}{c}\mathrm{EF}_{600-660 \mathrm{~nm}} \\
\text { (chlorophylls) }\end{array}$ \\
\hline $\begin{array}{l}\text { Basil } \\
\left(D_{10}\right)\end{array}$ & - & - & $\mathrm{A}_{417 \mathrm{~nm}}=2.53$ & 25.3 & $\begin{array}{c}\mathrm{A}_{598 \mathrm{~nm}} \\
=0.19569 \\
\mathrm{~A}_{652 \mathrm{~nm}} \\
=0.54651\end{array}$ & $\begin{array}{l}1.96 \\
5.46\end{array}$ \\
\hline $\begin{array}{l}\text { Thyme } \\
\left(D_{10}\right)\end{array}$ & - & - & $\mathrm{A}_{417 \mathrm{~nm}}=2.40$ & 24 & $\begin{array}{c}\mathrm{A}_{653 \mathrm{~nm}} \\
=0.80598 \\
\mathrm{~A}_{599 \mathrm{~nm}=} \\
0.24476\end{array}$ & $\begin{array}{l}8.06 \\
2.44\end{array}$ \\
\hline $\begin{array}{l}\text { Clove } \\
\left(\mathrm{D}_{1000}\right)\end{array}$ & $\begin{array}{c}\mathrm{A}_{279 \mathrm{~nm}}= \\
0.43739\end{array}$ & 4.37 & $\begin{array}{c}\mathrm{A}_{398 \mathrm{~nm}}= \\
0.07321\end{array}$ & 73.21 & 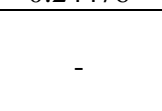 & - \\
\hline $\begin{array}{l}\text { Oregano } \\
\left(D_{100}\right)\end{array}$ & - & - & $\begin{array}{c}\mathrm{A}_{330 \mathrm{~nm}}= \\
0.74781 \\
\mathrm{~A}_{420 \mathrm{~nm}}= \\
0.14862\end{array}$ & $\begin{array}{l}74.78 \\
14.86\end{array}$ & - & - \\
\hline $\begin{array}{l}\text { Rosemary } \\
\left(D_{1000}\right)\end{array}$ & $\begin{array}{c}\mathrm{A}_{278 \mathrm{~nm}}= \\
0.35226\end{array}$ & 352.26 & $\begin{array}{c}\mathrm{A}_{327 \mathrm{~nm}}= \\
0.24690 \\
\mathrm{~A}_{398 \mathrm{~nm}}= \\
0.08065\end{array}$ & $\begin{array}{c}246.90 \\
80.65\end{array}$ & - & - \\
\hline $\begin{array}{l}\text { Sage } \\
\left(D_{1000}\right)\end{array}$ & $\begin{array}{c}\mathrm{A}_{270 \mathrm{~nm}}= \\
0.20093\end{array}$ & 200.93 & $\begin{array}{c}\mathrm{A}_{330 \mathrm{~nm}}= \\
0.16186 \\
\mathrm{~A}_{398 \mathrm{~nm}}= \\
0.08787\end{array}$ & $\begin{array}{l}161.86 \\
87.00\end{array}$ & - & - \\
\hline $\begin{array}{l}\text { Cinnamon } \\
\left(D_{1000}\right)\end{array}$ & $\begin{array}{c}\mathrm{A}_{278 \mathrm{~nm}}= \\
0.34855\end{array}$ & 348.55 & $\begin{array}{c}\mathrm{A}_{399 \mathrm{~nm}}= \\
0.09078\end{array}$ & 90.78 & - & - \\
\hline $\begin{array}{l}\mathrm{EPC} \\
\left(\mathrm{D}_{100}\right)\end{array}$ & $\begin{array}{c}\mathrm{A}_{280 \mathrm{~nm}}= \\
1.04179\end{array}$ & 104.18 & $\begin{array}{c}\mathrm{A}_{330 \mathrm{~nm}}= \\
0.55168 \\
\mathrm{~A}_{420 \mathrm{~nm}}= \\
0.15384\end{array}$ & $\begin{array}{l}55.17 \\
15.38\end{array}$ & - & - \\
\hline
\end{tabular}

The extraction efficiency was dependent on the polarity of the compounds found in the aromatic herbs and on the solvent polarity. In this case, a polar solvent was used for the extraction (methanol), considered as a reference solvent for extracting phenolic compounds. According to Tab. 2 high values for $\mathrm{EF}_{\mathbf{2 2 0 - 2 8 0} \mathbf{n m}}$ were observed in case of cinnamon, rosemary, sage, EPC (EF=352, 348, 200 and 104 respectively). These aromatic herbs are rich in phenolic acids that are more polar molecules. The $\mathrm{EF}_{\mathbf{3 3 0 - 4 2 0} \mathbf{~ n m}}$ specific to flavonoids and quinones was high only in case of rosemary and sage $(\mathrm{EF}=246$ and 161 , respectively) and relatively low in case of oregano and $\mathrm{EPC}(\mathrm{EF}=14$ and 55). Basil and thyme were characterized by the presence of quinines and chlorophylls (less polar compounds); the EF was highest in case of thyme.

\section{Total phenolic content}

Fig. 5 presents the total phenolic content for plant extracts and EPC. The richest content of phenols was observed for rosemary followed by clove, cinnamon, oregano, thyme, basil and sage, in a range from 136.249 to 271.164. For EPC, the concentration of phenolic compounds was $206 \mathrm{mg} \mathrm{GAE} / 100 \mathrm{ml}$, comparing to the "theoretical" concentration of 217.35 calculated according to the percentage of each plant in the final EPC formula. The difference was not significant and can be attributed to the antagonistic effects of phenolic compounds in 
possible formation of stable intermolecular complexes (Peyrat-Maillard et al., 2003). On the other hand, there were shown previouslysynergistic effects between rosmarinic acidquercetin, rosmarinic acid-caffeic acid and antagonistic effect between:(+)-catechin/caffeic acid, caffeic acid/quercetin (Shetty and Lin, 2005).

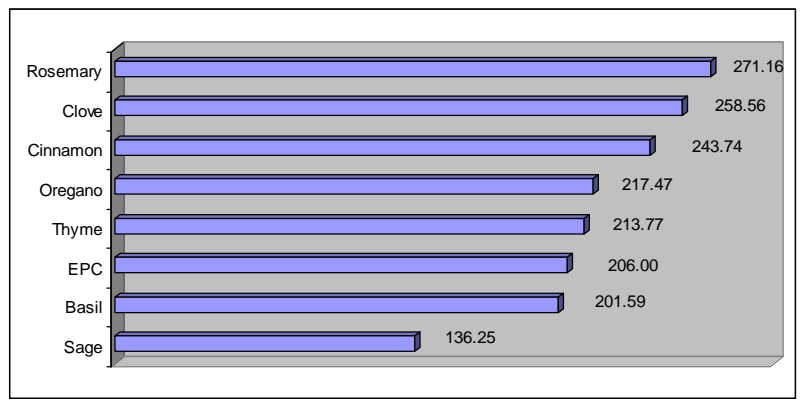

Fig. 5. Graphic representation of total phenolic content (mg GAE/100 ml extract)

\section{HPLC-DAD and LC-ESI(+)QTOF-MS characterisation of the plants and the new plant-based formula}

Fig. 6 represents the comparative HPLC -DAD chromatogram (A) and the LC-ESI (+) QTOF-MS base peak chromatogram (B) of the EPC product. The compound identification was based on their UV absorption spectra and calibrations with pure standards (for HPLCDAD), or by $\mathrm{m} / \mathrm{z}$ values of the released ions of protonated molecules $[\mathrm{M}+\mathrm{H}]^{+}$, identified from a specific data base (www.phenol-explorer.eu, http://www.ars-grin.gov/duke/plants.html).

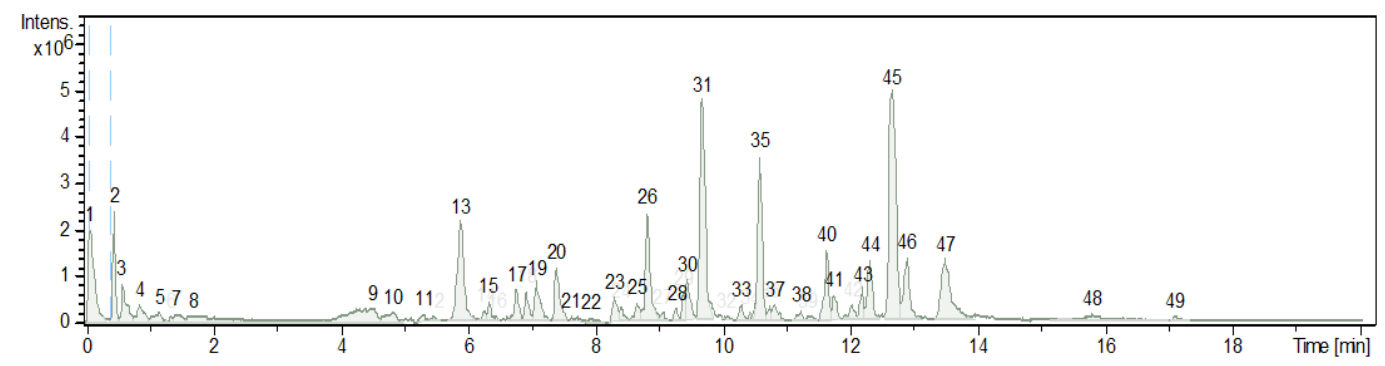

A

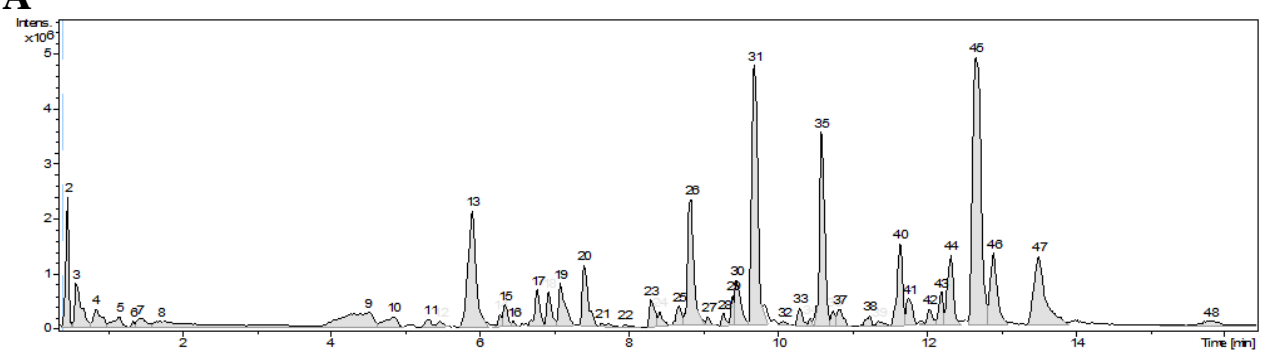

B

Fig. 6. Comparative HPLC-DAD chromatogram recorded at $270 \mathrm{~nm}(\mathrm{~A})$ and QTOF-MS base peak chromatogram of EPC extract (B)

In the individual HPLC-DAD chromatograms of basil, thyme, oregano, rosemary, cinnamon, sage, clove showed 24 major compounds (unpublished data), while EPC specific chromatogram presented 27 major compounds, identified in parallel with LC-ESI(+)QTOFMS.

Tab. 3 presents the compounds identified in each plant and in the new plant-based formula (EPC) by their protonated molecules and literature data (Shan et al., 2007, 
www.phenol-explorer.eu). In total 26 compounds were identified after comparison with published data and international database (Yáñez, 2013). According to Tab. 3 the common compounds found in each plants and in EPC are flavanols ((-) catechin, (-)- epicatechin).

The compounds can be grouped in the following classes: flavonols (quercetin, dihydroquercetin, isorhamnetin), flavanols ((-) catechin, (-)- epicatechin, epigallocatechin), isoflavones (daizdein), flavanones (naringenin, eriocitrin), stilbenes (resveratrol, transresveratrol, 3,4,5,4'-Tetramethoxystilbene), hydroxycinnaminic acid (sinapic acid, caffeic acid, chlorogenic acid, rosmarinic acid), isoflavonoids (biochanin A), lignans (secoisolariciresinol, 7-hydroxymatairesinol).

The new plant-based formula (EPC) can be characterized by the presence of flavonols (quercetin, dihydroquercetin, isorhamnetin), flavanols ((-) catechin, (-)- epicatechin, epigallocatechin), hydroxycinnaminic acids (caffeic acid, chlorogenic acid), stilbenes (resveratrol, trans-resveratrol, 3,4,5,4'-Tetramethoxystilbene) wich can confer the potential antimicrobial property.

In case of rosemary, clove, cinnamon, sage, thyme, basil, oregano same results were obtained by Cushnie and Lamb (2005), Shan et al (2007), Wojdylo et al. (2007) and Vauzour et al. (2012).

Tab. 3

LC-ESI(+)QTOF-MS data and tentative structure assignement of molecules separated from EPC product, based on the $\mathrm{m} / \mathrm{z}$ values and $\mathrm{t}_{\mathrm{R}},(\mathrm{Pn})$ values correspond to the chromatogram numbering in

Fig. 6

\begin{tabular}{|c|c|c|c|}
\hline Peak No $\left(P_{n}\right)$ & $\begin{array}{l}\text { Retention time } \\
\left(t_{R}, \min \right)\end{array}$ & $\begin{array}{c}{[\mathrm{M}+\mathrm{H}]^{+}} \\
\mathrm{m} / \mathrm{z}\end{array}$ & Tentative structure assignement \\
\hline $1(\mathrm{P} 9)$ & 4.5 & 185.0422 & Dihydrocaffeic acid \\
\hline $2(\mathrm{P} 10)$ & 4.9 & 243.0475 & Isopropyl 3-(3,4-dihydroxyphenyl)-2-hydroxypropanoate \\
\hline $3(\mathrm{P} 10)$ & 4.9 & 221.0662 & Sinapic acid \\
\hline $4(\mathrm{P} 11)$ & 5.3 & 355.1028 & Chlorogenic acid \\
\hline $5(\mathrm{P} 13)$ & 5.4 & 180.1026 & Caffeic acid \\
\hline $6(\mathrm{P} 13)$ & 5.7 & 595.1698 & Eriocitrin \\
\hline $7(\mathrm{P} 15)$ & 6.5 & 181.086 & Dihydrocaffeic acid, caffeic acid \\
\hline $8(\mathrm{P} 19)$ & 7.1 & 461.109 & (-)-Epigallocatechin 3-O-gallate, \\
\hline $9(\mathrm{P} 20)$ & 7.5 & 519.1147 & 1,5-Dicaffeoylquinic acid \\
\hline $10(\mathrm{P} 22)$ & 7.9 & 151.1116 & Hydroxytyrosol \\
\hline $11(\mathrm{P} 23)$ & 8.3 & 315.0873 & Isorhamnetin \\
\hline $12(\mathrm{P} 23)$ & 8.4 & 274.2752 & Naringenin \\
\hline $13(\mathrm{P} 25)$ & 8.4 & 274.2752 & Pelargonaldehide \\
\hline $14(\mathrm{P} 26)$ & 8.8 & 285.077 & Biochanin A \\
\hline $15(\mathrm{P} 26)$ & 8.8 & 230.2489 & Resveratrol, trans-resveratrol \\
\hline $16(\mathrm{P} 30)$ & 9.5 & 375.1823 & 7-Hydroxymatairesinol \\
\hline $17(\mathrm{P} 31)$ & 9.7 & 359.1123 & Rosmarinic acid \\
\hline $18(\mathrm{P} 35)$ & 10.6 & 142.7 & Quercetin, dihydroquercetin \\
\hline $19(\mathrm{P} 37)$ & 11.2 & 309.2433 & (-)-Epigallocatechin \\
\hline $20(\mathrm{P} 40)$ & 11.6 & 291.2329 & (-)-Catechin, (-)-Epicatechin \\
\hline $21(\mathrm{P} 41)$ & 11.8 & 621.2723 & Peonidin - 3- O- rutinoside \\
\hline $22(\mathrm{P} 42)$ & 12 & 273.2581 & Gallic acid \\
\hline $23(\mathrm{P} 43)$ & 12.2 & 293.2484 & Caffeoyl aspartic acid or p-Coumaroyl tartaric acid \\
\hline $24(\mathrm{P} 44)$ & 12.3 & 623.2887 & $\begin{array}{c}\text { Apigenin 7-O-diglucuronide or } \\
\text { Isorhamnetin 3-O-glucoside 7-O-rhamnoside } \\
\end{array}$ \\
\hline $25(\mathrm{P} 45)$ & 12.6 & 607.2944 & $\begin{array}{l}\text { Diosmin, neodiosmin, or } \\
\text { Peonidin }-3 \text { - O- rutinoside }\end{array}$ \\
\hline $26(\mathrm{P} 46)$ & 12.9 & 607.2939 & $\begin{array}{c}\text { Diosmin, neodiosmin, or } \\
\text { Peonidin - 3- O- rutinoside }\end{array}$ \\
\hline $27(\mathrm{P} 47)$ & 13.5 & 467.3176 & Quercetin 3-O-glucoside (isoquercetin) \\
\hline
\end{tabular}




\section{CONCLUSION}

According to the aims of this study, we obtained and characterized a new aromatic plant-based formula, intended to be used as an antimicrobial food supplement.

The formula contained plants which proved to have antimicrobial action (rosemary, clove, cinnamon, oregano, thyme, basil and sage). The characterization of individual plant ingredients and final product as methanolic extracts was made using UV-Vis spectroscopy, LC-ESI(+)QTOF-MS and HPLC-DAD analysis.

1. Based on UV-Vis spectral fingerprint, it was calculated the extraction efficiency of different phenolic derivatives, which were selectively extracted. Higher values for phenolic acids were observed for cinnamon, rosemary, sage, while rosemary and sage had higher values for flavonoids.

2. The richest content of phenolic derivatives was observed for rosemary followed by clove, cinnamon, oregano, thyme, basil and sage, in a range from 136.249 to 271.164. For EPC, the concentration of phenolic compounds was $206 \mathrm{mg}$ GAE/100 ml, comparing to the "theoretical" concentration of 217.35 calculated according to the percentage of each plant in the final EPC formula. The difference was not significant and can be attributed to the antagonistic effects of phenolic compounds in possible formation of stable intermolecular complexes.

3. Using LC-ESI(+)-QTOF-MS and HPLC-DAD as accurate methods to identify the main biomarkers present in the aromatic herbs and EPC, we separated 27 molecules and made their tentative structure assignement, based on international databases. The main biomarkers of EPC were identified to be flavonols (quercetin, dihydroquercetin, isorhamnetin), flavanols ((-) catechin, (-)- epicatechin, epigallocatechin), hydroxycinnaminic acids (caffeic acid, chlorogenic acid), stilbenes (resveratrol, transresveratrol) which may confer its antimicrobial potential.

In conclusion, in order to determine the authenticity and the quality of aromatic herbs and plant-based formulas there are recommended combined UV-Vis, LC-ESI(+)-QTOF-MS and HPLC-DAD analyses, as accurate methods to identify the composition of extracts with antimicrobial effects.

\section{REFERENCES}

1. Alzoreky, N. S. Al. (2009). Antimicrobial activity of pomegranate (Punica granatum L.) fruit peels. Int. J. of Food Microbiol. 34: 244-248

2. Braga, L. J. W. Shupp, C. Cummings (2005). Pomegranate extract inhibits Staphylococcus aureus growth and subsequent enterotoxin production, J. Ethnopharmacol. 96:335-339

3. Cushnie T. and A. J. Lamb (2005). Antimicrobial activity of flavonoids, In International J..Antimicrobial Agents. p. 343-356

4. Delmas Dominique, F. Mazué, D. Colin, P. Dutartre, N. Latruffeet (2009). Development of promising naturally derived molecules to improve therapeutic strategies, In Flavonoids: biosynthesis, biological effects and dietary sources, Nova Science Publishers, Inc, Ed. Raymond B. Keller, p. 181213

5. Folin, O. and V. Ciocalteu (1927). On tyrosine and tryptophane determinations in proteins. J. Biol. Chem. 73: 627-629.

6. Ma C.-M. and M. Hattori (2009). Flavan-3-ol Monomers and Condensed Tannins in Dietary and Medicinal Plants In Flavonoids: biosynthesis, biological effects and dietary sources, Nova Science Publishers, Inc, Ed. Raymond B. Keller, p. 273-291

7. Oszmiański J. and A. Wojdylo (2005). Aronia melanocarpa phenolics and their antioxidant activity, Eur. Food. Res. Technol. 221: 809-813 
8. Peyrat-Maillard M. N., M. E. Cuvelier, C. Berset (2003). Antioxidant activity of phenolic compounds in 2,2'-azobis (2-amidinopropane) dihydrochloride (AAPH)-induced oxidation: Synergistic and antagonistic effects, J. Am. Oil Chem.Soc. 80(10): 1007-1012

9. Rossetto, M., P. Vanzani, L. Zennaro, F. Mattivi, U. Vrhovsek, M. Scarpa, A. Rigo (2002). Synergistic antioxidant effect of catechin and malvidin-3-glucoside on free radical-initiated peroxidation of linoleic acid in micelles. Arch. Biochem. Biophys. 408(2): 239-245.

10. Santos-Buelga C., S.González-Manzano, M. Dueñas, A. M. González-Paramás (2012). Analysis and Characterisation of Flavonoid Phase II Metabolites in Recent Advances in Polyphenol Research, Ed.Véronique Cheynier, Pascale Sarni-Manchado, Sétphane Quideau, 249-287

11. Shan B., Y.-Z. Cai, J. D. Brooks, H. Corke (2007). The in vitro antibacterial activity of dietary spice and medicinal herb extracts, International Journal of Food Microbiology 117:112-119

12. Shetty K. and Y.-T. Lin (2005). Phenolic Antimicrobials from Plants for Control of Bacterial Pathogens in Functional Foods and Biotechnology, Ed CRC Press Kalidas, 285-231

13. Silva Ncc and F. Júnior A (2010). Biological properties of medicinal plants: a review of their antimicrobial activity, J. of Venomous Anim. and Toxins incl. Tropical Dis. 16: 402-413

14. Tajkarimia, M.M., S.A. Ibrahim, D.O. Cliver, 2010, Antimicrobial herb and spice compounds in food. Food Control. 21: 1199-1218

15. Vattem D. A. and K. Shetty (2005). Biochemical Markers for Antioxidant Functionality, In Functional Foods and Biotechnology, Ed CRC Press, p. 229-253

16. Vauzour D., K. Vafeiadou, J. P. E. Spencer (2012). Polyphenols, In Phytonutrients, WilleyBlackwell Publishing Ltd, Ed: A. Salter, Helen, Weiseman, G.Tucker, 110-146

17. Wojdyło Aneta, J. Oszmianśki, R. Czemerys (2007). Antioxidant activity and phenolic compounds in 32 selected herbs. Food Chemistry 105: 940-949

18. Yáñez, J. A., C. Remsberg, J. K. Takemoto, K. R. Vega-Villa, P. K. Andrews, C. L. Sayre, S. E Martinez, N. M. Davies (2013). Polyphenols and Flavonoids: An Overview, In Flavonoid Pharmacokinetics. Methods of Analysis, Preclinical and Clinical Pharmacokinetics, Safety and Toxicology, Ed N. M. Davies and J. A.Yañez, p. 1-71 